\title{
Smart Antenna UKM Testbed for Digital Beamforming System
}

\author{
Mohammad Tariqul Islam, ${ }^{1}$ Norbahiah Misran, ${ }^{1,2}$ and Baharudin Yatim ${ }^{1}$ \\ ${ }^{1}$ Institute of Space Science (ANGKASA), National University of Malaysia, 43600 UKM Bangi, Selangor Darul Ehsan, Malaysia \\ ${ }^{2}$ Department of Electrical, Electronics \& System Engineering, National University of Malaysia, 43600 UKM Bangi, \\ Selangor Darul Ehsan, Malaysia
}

Correspondence should be addressed to Mohammad Tariqul Islam, tariqul@ukm.my

Received 4 May 2008; Revised 11 November 2008; Accepted 6 January 2009

Recommended by Jiri Jan

\begin{abstract}
A new design of smart antenna testbed developed at UKM for digital beamforming purpose is proposed. The smart antenna UKM testbed developed based on modular design employing two novel designs of L-probe fed inverted hybrid E-H (LIEH) array antenna and software reconfigurable digital beamforming system (DBS). The antenna is developed based on using the novel LIEH microstrip patch element design arranged into $4 \times 1$ uniform linear array antenna. An interface board is designed to interface to the ADC board with the RF front-end receiver. The modular concept of the system provides the capability to test the antenna hardware, beamforming unit, and beamforming algorithm in an independent manner, thus allowing the smart antenna system to be developed and tested in parallel, hence reduces the design time. The DBS was developed using a high-performance TMS320C6711 ${ }^{\mathrm{TM}}$ floating-point DSP board and a 4-channel RF front-end receiver developed in-house. An interface board is designed to interface to the ADC board with the RF front-end receiver. A four-element receiving array testbed at $1.88-2.22 \mathrm{GHz}$ frequency is constructed, and digital beamforming on this testbed is successfully demonstrated.
\end{abstract}

Copyright (C) 2009 Mohammad Tariqul Islam et al. This is an open access article distributed under the Creative Commons Attribution License, which permits unrestricted use, distribution, and reproduction in any medium, provided the original work is properly cited.

\section{Introduction}

Smart antenna with digital beamforming (DBF) is regarded as one of the key components to meet the ever increasing appetite for higher data rates. Smart antenna technology dramatically improves the interference-suppression capability and greatly increases frequency reuse, resulting in increased capacity. Smart antenna with its beamforming capability optimizes the signal-to-noise performance or power consumption at both ends of the links. Advancement in powerful low-cost digital signal processor (DSP), generalpurpose processors, field programmable gate array (FPGA), application-specific integrated circuits (ASICs), as well as innovative software-based signal processing techniques (algorithms) or software-defined radio (SDR), has allowed the development of smart antenna system to progress rapidly and make the smart antennas practical for cellular communications systems [1].

The beamforming is a key technology in smart antenna system which is a process in which each user signal is multiplied with a complex weight vectors that adjust the magnitude and phase of the signal from each antenna element [2-5]. Hence, the array forms a transmit beam in the desired direction and minimizes the output in the interferer directions. A beamformer appropriately combines the signals received by different elements of an antenna array to form a single output. The DBF system provides several advantages over analog beamforming techniques. First, analog array system uses expensive microwave phase shifters and attenuators for each element. Second, the signal processing capability, such as adaptive beamforming, is limited. However, there are still challenges in the practical implementation of high-performance DBF array system [6]. Classically, this is achieved by minimizing the mean square error (MSE) between the desired output and the actual array output. This principle has its roots in the traditional beamforming employed in sonar and radar systems [7-13].

Investigating the performance of highly sophisticated wireless systems, in particular the smart antenna systems, is a difficult task. In most cases, this can only be performed via simulation, which means modeling complex behavior 
by simpler mathematical descriptions. Software simulation, for example, MATLAB software with its highly accurate double-precision numerical environment is on the one hand a perfect tool for the investigation of algorithms. On the other hand, many imperfections of the realworld are neglected [14]. A testbed is generally used for research which is a vehicle for further development, for verification of algorithms, or ideas under real-world or real-time conditions. This results in the requirement for scalability, modularity, and extendibility [14]. The advantage of testbed is to reduce the investment risk of the new product in case the new technology would hide unforeseen challenges.

Recently, there has been a great effort to build the smart antenna system testbed (SATB) to meet the ever demanding channel capacity for the future generation broadband mobile communication systems [15-17]. There are testbeds reported in the literature focusing on various wireless technologies. The TSUNAMI project [18] in Europe was aimed at promoting research and development in adaptive antennas. The testbed reported by Virginia Tech lab [19] is a $2 \times 2$ broadband MIMO. Iospan Wireless Inc. and Stanford University also reported in [14] a smart antenna testbed one in downlink and another in uplink. These SATBs are designed based on narrowband antennas employing conventional dipole, slots, TEM horns, reflectors antenna, and so forth that made the antennas bulky and heavy. Aesthetic appearances of these structures are adversely affected by big bulky antennas. Microstrip technology meets the requirement of a compact and low-profile system due to its light weight, low production cost, ease of fabrication, and conformability with RF circuitry $[20,21]$. However conventional microstrip antenna or array suffers from very narrow bandwidth. This set the design challenges of developing a broadband microstrip antenna that can cover the radio band (1.88-2.22 GHz).

The objective of this work is to reduce the antenna size and complexity of the system without compromising the digital beamforming capability. Furthermore, microstrip slot antennas are selected for the design of the array due to their compactness. The remainder of the paper is organized as follows. Section 2 describes the system architecture and hardware implementation. Section 3 discusses the UKM testbed measurement results, and finally Section 4 concluded the paper.

\section{System Architecture and Hardware Implementation}

The novel SATB developed at UKM (UKM testbed) is developed based on modular concept employing two novel designs of four-element microstrip patch antenna array and DSP-based DBS, which allows the exploitation of digital beamforming. The testbed is designed as a receiver unit. A block diagram of UKM testbed receiver system architecture is shown in Figure 1. The testbed receiver system composed of antenna system, radio unit, and digital signal processing baseband section.

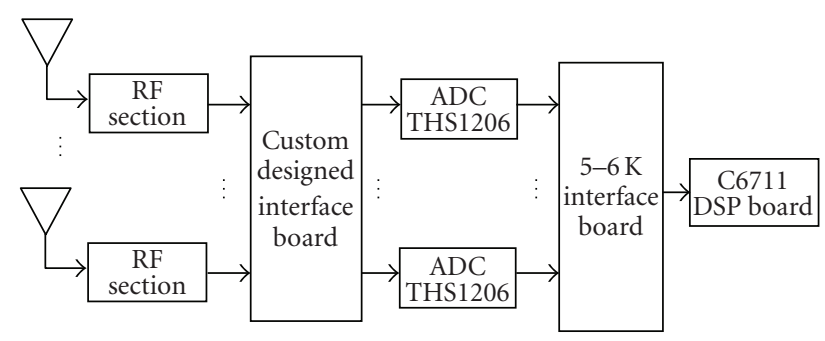

FIGURE 1: Block diagram of UKM testbed receiver.

TABLE 1: The LIEH-shaped MPA design specification.

\begin{tabular}{ll}
\hline RF parameter & Values \\
\hline Superstrate & RT $5880\left(\varepsilon_{r 1}=2.2, h_{1}=1.5748 \mathrm{~mm}\right)$ \\
Substrate & Air $\left(\varepsilon_{0}=1, h_{0}=16 \mathrm{~mm}\right)$ \\
Rectangular patch & $\begin{array}{l}\text { Width and Length, } \\
\{W, L\}=\{79,41\} \mathrm{mm}\end{array}$ \\
Feed position & $\begin{array}{l}f p=8.5 \mathrm{~mm} \text { from bottom edge of } \\
\text { the patch }\end{array}$ \\
Slots parameters $(\mathrm{E})$ & $\{l s, s, w s\}=\{37,16,1\} \mathrm{mm}$ \\
Slots parameters $(\mathrm{H})$ & $\{l h, w h, s h\}=\{18,19,2\} \mathrm{mm}$ \\
Probe length & $h_{p}=14 \mathrm{~mm}$ along $y$ axis $l_{p}=25 \mathrm{~mm}$ \\
& along $x$ axis
\end{tabular}

The radiating element, the LIEH-shaped microstrip patch antenna (MPA), is arranged in a $4 \times 1$ linear array configuration and with interelement spacing of $68 \mathrm{~mm}$ (or $0.50 \lambda)$ at $2.2 \mathrm{GHz}$. The total dimension of the array is $120 \mathrm{~mm}$ (width) by $285 \mathrm{~mm}$ (length) with the size of the ground plane equals to $370 \mathrm{~mm} \times 200 \mathrm{~mm} \times 1 \mathrm{~mm}$. The design parameters for the LIEH-shaped MPA are shown in Table 1. The LIEH array antenna is constructed using two dielectric layer arrangements, where a thick air-filled substrate was sandwiched between top-loaded dielectric substrate or superstrate with inverting radiating patch and an aluminum ground plane [22]. The array antenna is designed based on LIEH-shaped microstrip patch which used contemporary design techniques, namely, the Lprobe feeding, inverted patch, and slotted patch techniques to meet the design requirement. The geometry of the $4 \times 1$ uniform linear LIEH array antenna is shown in Figure 2.

A commercial electromagnetic simulator Sonnet Suite em simulator was used to simulate the design. The fabricated antennas were measured using the Agilent PNA E8358A network analyzer, Agilent ESG-DP series E4436B signal generator, Advantest R3131A spectrum analyzer, and the standard gain LPDA-0803 log periodic dipole antenna. Measurement was conducted in the open field. The array achieves an impedance bandwidth of $17.32 \%$ (at VSWR $\leq$ 1.5), maximum achievable gain of $11.9 \pm 1 \mathrm{dBi}$ and $20 \mathrm{~dB}$ crosspolarization level [22]. 


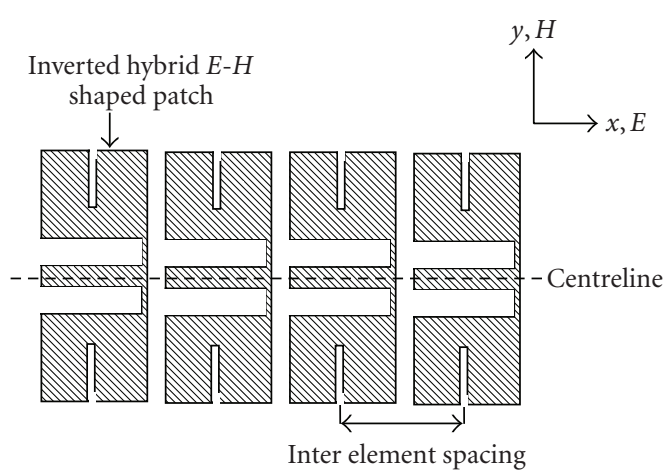

(a)

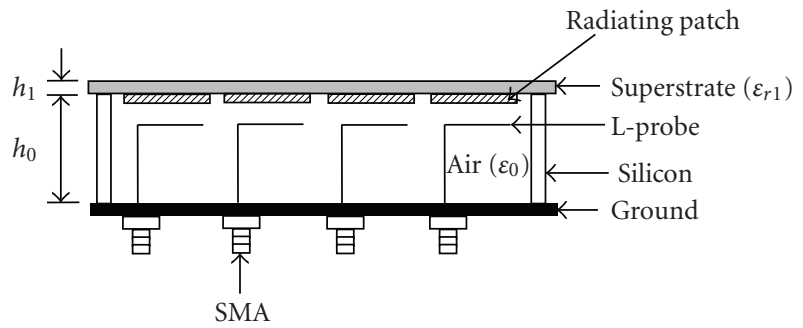

(b)

Figure 2: (a) Top view and (b) side view of the $4 \times 1$ LIEH patch elements.

The radiation characteristics of the LIEH patch antenna measured in free space range are shown in Figure 3. It shows the E-plane and $\mathrm{H}$-plane radiation patterns of the hybrid patch at resonance frequency of $1.92 \mathrm{GHz}$ and $2.15 \mathrm{GHz}$. The experimental results agree well with the simulation results (not shown in this paper). In the Eplane, the $3 \mathrm{~dB}$ beam width is $60^{\circ}$ at $1.92 \mathrm{GHz}$ and $50^{\circ}$ at $2.15 \mathrm{GHz}$. The peak crosspolarization is $-25 \mathrm{~dB}$ at $1.91 \mathrm{GHz}$ and $-30 \mathrm{~dB}$ at $2.15 \mathrm{GHz}$. The radiation pattern is virtually symmetry in the H-plane but asymmetries in the E-plane. The asymmetry characteristic of the copolarization pattern is clearly shown in Figure 3. The LIEH patch antenna shows that the cross-polarization level increases with resonant frequency and thickness [23]. The $\mathrm{H}$-plane radiation pattern shows a slightly broader $3 \mathrm{~dB}$ beamwidth about $75^{\circ}$. The peak cross-polarizations are $-11.87 \mathrm{~dB}$ and $-9.82 \mathrm{~dB}$ at the respected resonant frequencies. The improvement in the crosspolarization characteristics of the patch is due to the embedded parallel slot which reduces the current flow in $\mathrm{H}$ plane direction as observed earlier. Noted in this figure, the crosspolarization in the $\mathrm{H}$-plane is considerably higher than the E-plane. Similar observations have been reported in the literature [24]. This cross-polarization is generated by the leaky radiation of the slots [24] and also due to the substrate thickness [25].

Figure 4 shows the measured coupling between the elements $S_{12}, S_{13}$, and $S_{14}$ of the $4 \times 1$ LIEH array antenna, with element 1 taken as the reference element. It can be seen that the coupling between the reference element and other elements decays over elements spacing. As shown in the figure, the magnitude of $S_{12}, S_{13}$, and $S_{14}$ remains flat over the pass band, and the maximum mutual coupling is between element 1 and element $2\left(S_{12}\right)$ with the maximum value of $-12.2 \mathrm{~dB}$ in the operating bandwidth. The minimum mutual coupling is $-41.83 \mathrm{~dB}$ between element 1 and element 4 $\left(S_{14}\right)$. Table 2 shows the simulated and measured values of the interelement coupling between all elements of the array.

One of the fastest floating-point platforms available, the Texas Instruments (TI) TMS320C67 DSP capable of 900 MFLOPS, was selected as the computational platform for the DBS. The radio frequency (RF) receiver front-ends accommodate a multichannel two-stage down conversion

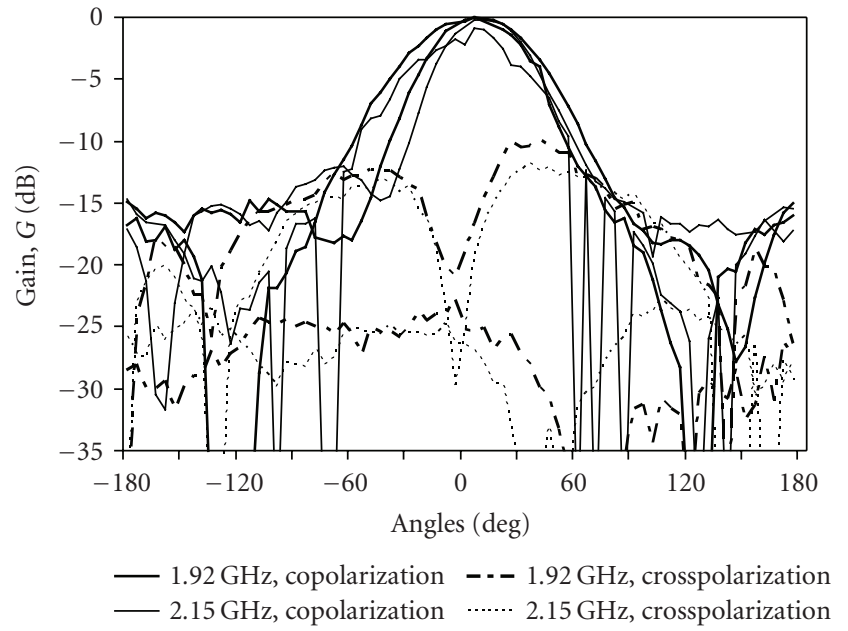

Figure 3: Measured E- and H-plane normalized radiation patterns at two resonant frequencies of $1.92 \mathrm{GHz}$ and $2.15 \mathrm{GHz}$.

TABLE 2: Interelement coupling for each element of $4 \times 1 \mathrm{LIEH}$.

\begin{tabular}{lccc}
\hline & $S_{12}(2 \mathrm{GHz})$ & $S_{13}(2 \mathrm{GHz})$ & $S_{14}(2 \mathrm{GHz})$ \\
\hline Simulated & $15 \mathrm{~dB}$ & $23 \mathrm{~dB}$ & $34 \mathrm{~dB}$ \\
Measured & $12 \mathrm{~dB}$ & $21 \mathrm{~dB}$ & $30 \mathrm{~dB}$ \\
\hline
\end{tabular}

between the RF section and the baseband section. Center frequency of $2040 \mathrm{MHz}$ is used in the custom designed frontends due to the propagation similarities compared to the worldwide $3 \mathrm{G}$ radio band $(1.88 \mathrm{GHz}-2.22 \mathrm{GHz})$ and the availability of standard components at this frequency. The DBS front-end is composed of four parallel RF channels which filtered, amplified, and downconverted the incoming signal from the antenna into eight complex baseband signals $(I \& Q)$ using the $I \& Q$ demodulators. These signals are fed to the analog-to-digital conversion (ADC) board for data conversion.

Figure 5 shows the simplified block diagram of RF front-end of the UKM testbed. The RF section of the testbed composes of four parallel RF channels which are filtered and amplified by Trilithic RF BPFs centered 


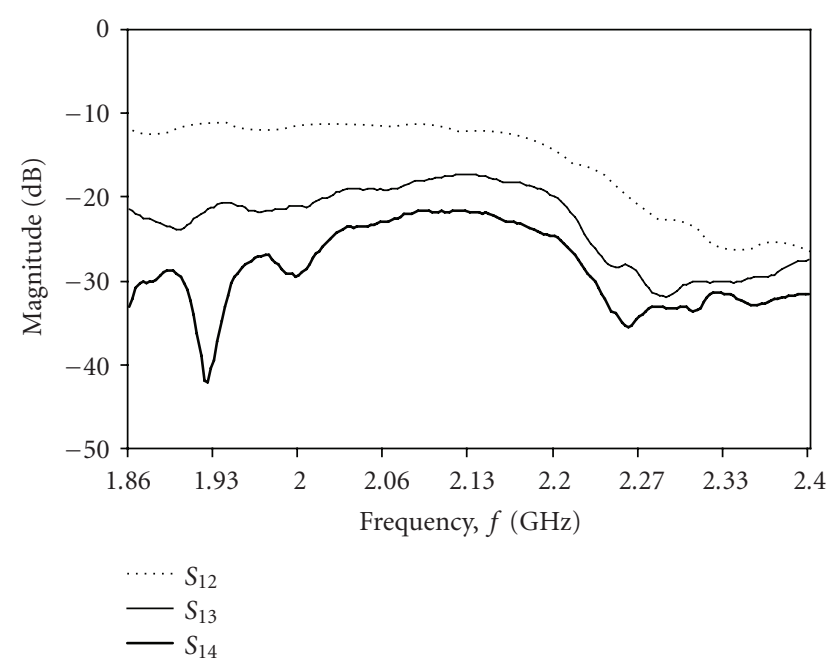

Figure 4: Measured coupling between element 1 and other elements of the $4 \times 1$ LIEH-shaped array.

at $2040 \mathrm{MHz}$ and MiniCircuits ZHL-1724HLN low-noise amplifiers, respectively. The incoming signal is downconverted by MiniCircuits ZEM-4300 MHz double-balanced mixers and Trilithic IF BPFs centered at $68 \mathrm{MHz}$. The eight complex baseband signals are generated using the ZFMIQ$70 \mathrm{D}$ demodulator. The LNA and IF amplifiers run on 15 volts $\mathrm{DC}$, and the power consumption per channel is measured at 15.8 watts, which provided a combined power consumption of 63.2 watts for the four-element RF front-end. The LO signal for the mixers $(13 \mathrm{dBm}$ drive level $)$ is driven from a single source to keep the phase relationship constant between the branches. An Agilent E4436B ESG series signal generator is utilized to generate the $1972 \mathrm{MHz}$ LO signal. The 1 to 4 Mini-Circuits ZN4PD1-50 power splitter is used to deliver the signal to the mixer. The Agilent 6653A DC power supply is used to drive the amplifier.

The ADC is performed with the multichannel TI THS1206M EVM, which is mated to the Texas Instruments C67 DSP board through TI 5-6 K Interface board. Since an 8-channel ADC board was not available on a single board, two 4-channel TI THS1206M EVM boards were placed on top of another. The ADC board has been modified for stacking the two ADC boards to get eight baseband channels. Custom-designed boards were developed to interface with ADC board. Figure 6 shows the developed RF front-end for UKM testbed. The DBS consists of a four-layer rake. The dimension of each layer is 24 inches $\times 14$ inches and mounted on an aluminum metal plate above the Perspex for grounding and mechanical support. The bottom three layers are used to accommodate all the components and the top layer for the screening purpose only. The power connections are run beside the board from the DC power supply.

The demodulated antenna signals are received from SMA connector of MiniCircuits low-pass filter (LPF), but the analog input of the ADC board is the combination of header/socket. To feed the LPF signal into the analog input of $\mathrm{ADC}$, the header/socket connector is required to be modified for complying with SMA connector of the
LPF filter. The analog input of the THS1206M EVM is a 20 -pin male header $(2$ rows $\times 10$ pos $)$. There is a 20 -pin socket on the bottom side and a 20-pin male header on the top side of the THS1206M EVM. These are passingthrough connectors (shorted top to bottom). The only output available from analog signal sources is from SMA male connectors. Therefore, a female SMA connector is required to adapt to breakout the signal for THS1206M EVM board. A shielded ribbon cable is utilized with mating header that fits on the 20-pin male header. These two male header connectors remain the same when THS1206M EVM is stacked on the 5-6 K Interface board. A 20-pin female socket which is connected by ribbon cable is used to plug into the connector of the 5-6 K interface board. The other end of the ribbon cable is soldered to mate SMA connector.

In order to get the proper voltage level between $1.5 \mathrm{~V}$ to $3.5 \mathrm{~V}$ for THS1206 M EVM, the voltage signal is shifted to $2.50 \mathrm{~V}(\mathrm{REFM}+\mathrm{REFP} / 2)$. Figure 7 shows the circuit diagram of voltage level shifter circuit. The analog input signal is shifted to the analog input range of THS1206 $(1.5 \mathrm{~V}$ to $3.5 \mathrm{~V}$ ) by using this circuit board. The op-amp is configured with a resistor divider as an inverting amplifier with a unity gain. Two units of 4-input TL084CN are employed in order to get the 8 input signals. The output of the voltage divider circuit is tapped into the noninverting input of the TL084CN op-amp. A high-resolution THS 1206 ADC and Nyquist sampling technique are employed to solve signal digitization error. Figure 8 shows the developed UKM testbed system.

The developed UKM testbed is composed of $4 \times 1$ LIEH array antenna, four RF branches, eight-channel ADC, TMS320C6711 DSP board, and Pentium host PC. The UKM testbed receiver system implemented the DBF which is based on the constant modulus algorithm (CMA) [8]. The DSP with its beamforming algorithms generates the required weight vector based on the angle of arrival of the intended user. The CMA algorithm is simpler to implement and does not require any synchronization and reference signal. The beamforming algorithm is implemented on C67 floating point DSP for the low-cost noncoherent testbed system. It does not waste the bandwidth for the training signal. A host PC is used to collect data in real-time and offline processing. The data received from LIEH array antenna and the processed RF front-end signal is recorded online utilizing host PC. The data collected by the host PC is passed to the MATLAB environment for postprocessing and display in offline. Table 3 summarizes the specification of the UKM testbed receiver.

\section{Measurement Results and Discussions}

A testbed is set up in the microwave lab to evaluate system performance. The DBF measurement result is presented in this section. A single-tone test is performed for the evaluation of the UKM testbed performance. An Agilent 54622 D-mixed signal digital oscilloscope is used after the LPF to observe the baseband signal waveform. Figure 9 shows the experimental setup for the evaluation of beamforming algorithm. 


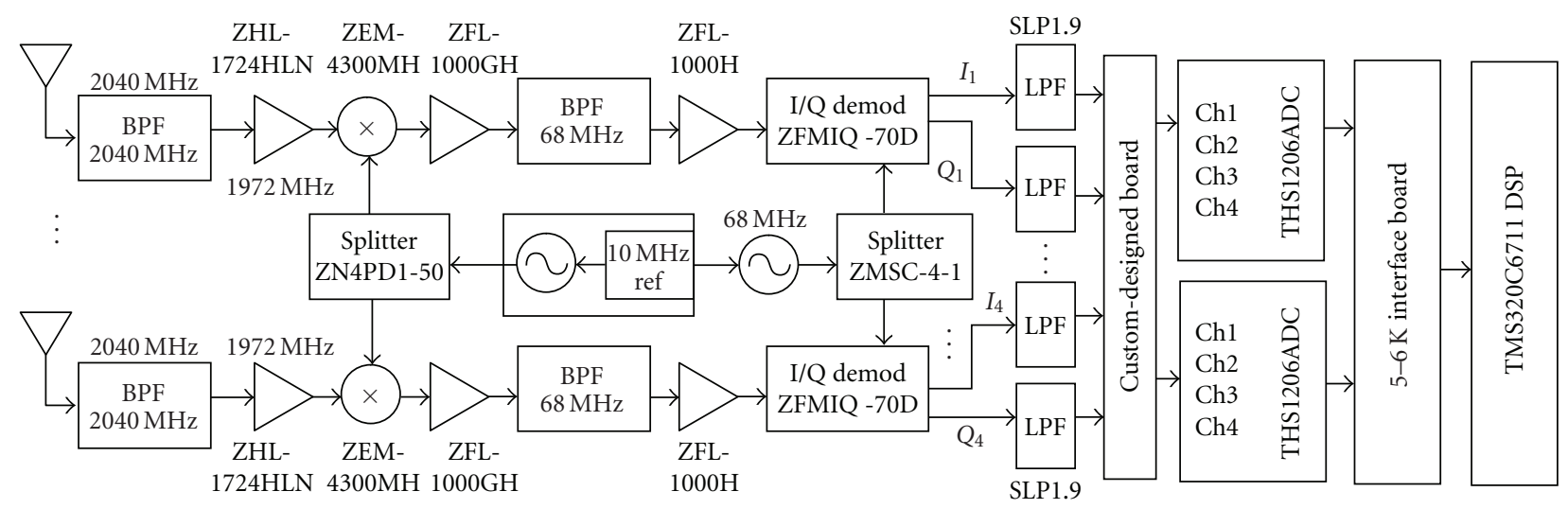

FIGURE 5: Simplified system block diagram of DBS system for the UKM testbed.

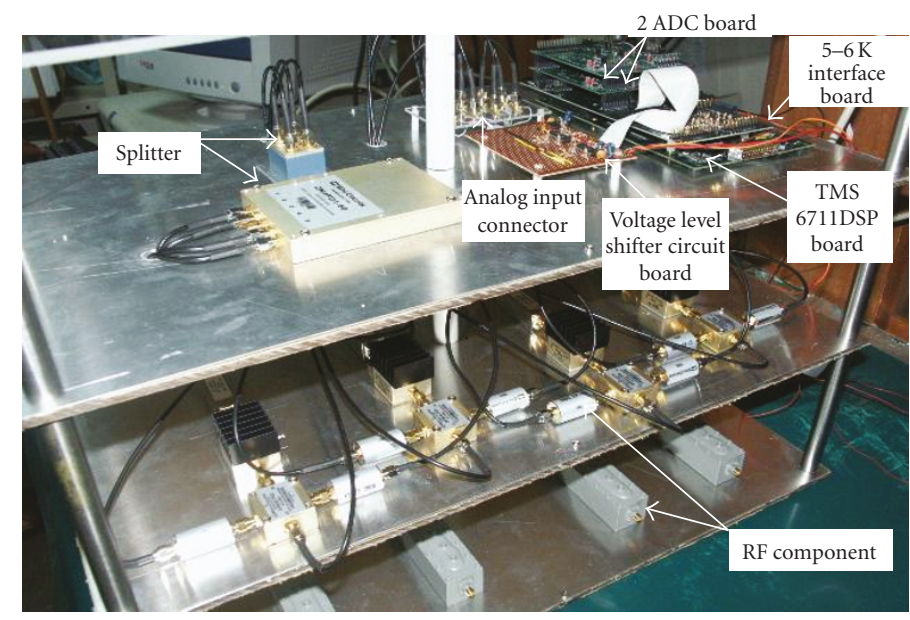

FIGURE 6: The developed RF front-end for UKM testbed.

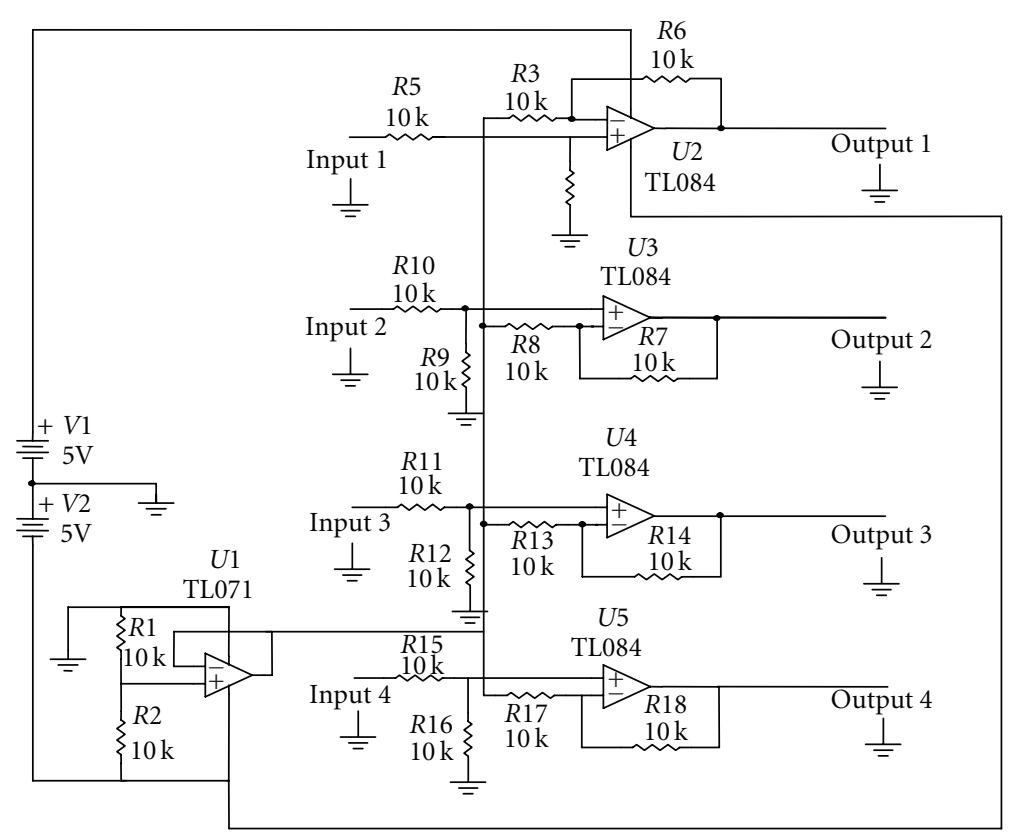

FIgURE 7: Voltage level shifter circuit board. 


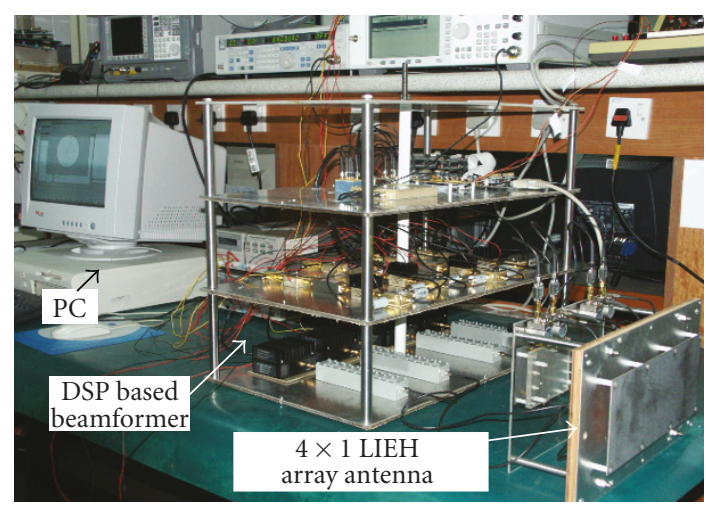

FIgURE 8: Constructed UKM testbed receiver system.

TABLE 3: Specification of UKM testbed receiver.

\begin{tabular}{ll}
\hline RF parameter & Values \\
\hline Antenna & $\begin{array}{l}4 \times 1 \text { uniform linear array } \\
\text { LIEH-shaped MPA }\end{array}$ \\
Antenna element & $\begin{array}{l}\text { TMS320C6711 (Texas } \\
\text { Instruments) }\end{array}$ \\
DSP & $2035-2070 \mathrm{MHz}$ \\
Operating frequency & $750 \mathrm{KHz}$ \\
$\begin{array}{l}\text { Maximum signal } \\
\text { bandwidth } \\
\text { ADC resolution } \\
\text { IF frequency }\end{array}$ & $12 \mathrm{bit}$ \\
Sampling period & $68 \mathrm{MHz}$ \\
$\begin{array}{l}\text { Transmitting antenna } \\
\text { power (without amplifier) }\end{array}$ & $1.11 \mu \mathrm{s}(900 \mathrm{KHz}) / \mathrm{channel}$ \\
Receiver output & $10 \mathrm{dBm}$ \\
$\begin{array}{l}\text { Modulation } \\
\text { Receiver input impedance }\end{array}$ & $130 \mathrm{mV}$ \\
\hline
\end{tabular}

A continuous wave of $2040.010 \mathrm{MHz}$ RF signal is transmitted by transmitting the antenna. The signal is received by the $4 \times 1$ LIEH array at the front end of UKM testbed receiver. The multichannel signal splitter is used to give input to the mixer from LO. The RF tone is downconverted into a $10 \mathrm{kHz}$ baseband signal with an LO set at $1972 \mathrm{MHz}$. The $I$ and $Q$ signals for different channels are recorded using Agilent $54622 \mathrm{D}$ digital oscilloscope from the LPF before they are sent down to the ADC board.

Table 4 summarizes the amplitudes of $I$ and $Q$ signals for all four channels. In the measurement the phase of $I$ signal of channel 1 is considered as zero and the well-aligned phase front demonstrates a good broad side reception. The baseband signal is recorded as $10.10 \mathrm{kHz}$. There is no disruption observed in the signal.

The signal received by the ADC after conversion using code composer studio (CCS) [26] is presented in Figure 10. In this figure, the first signal is $I$ signal and the second signal is $Q$ signal before DBF. These signals share the same shape since both signals are from the same types of demodulator
TABLE 4: Measured I and Q signals amplitudes for 4 channels.

\begin{tabular}{lcc}
\hline & $I(\mathrm{mV})$ & $\mathrm{Q}(\mathrm{mV})$ \\
\hline Channel 1 & 125 & 127 \\
Channel 2 & 127 & 122 \\
Channel 3 & 125 & 119 \\
Channel 4 & 106 & 127 \\
\hline
\end{tabular}

source. As can be seen from these figures, the amplitude of both types of signal is constant, and the phase difference between $I$ and $Q$ signal is $90^{\circ}$. A small disruption is observed in the signal due to the signal generators and interchannel interference, which is caused by the RF component and RF cable used for the measurement. There is no noticeable phase difference observed between both channels. The original data samples are shown along with the envelope.

The following results are carried out to demonstrate the UKM testbed as a beamforming system. The resulted weight vectors are used in MATLAB to plot the antenna response pattern. The data is taken for a different angle of $0^{\circ}, 30^{\circ}$, and $-30^{\circ}$ to plot the beampattern. The $I$ and $Q$ baseband signals are digitized through ADCs and processed by DSP. The architecture is designed to retain all the amplitude and phase information for each antenna element through downconversion and signal recovery, so that, DBF algorithms can be applied. Once each channel data has been recovered, the DBF algorithm is calculating the weight vectors to form the antenna pattern. The DBF allows the antenna radiation pattern to be scanned over a wide range of angles without using the associated expensive RF attenuator and phase shifter hardware. Complex weighting coefficients are multiplied with each channel data to synthesize the pattern at the desired position.

Figure 11 demonstrates the baseband DBF radiation pattern at $0^{\circ}, 30^{\circ}$, and $-30^{\circ}$. The $3 \mathrm{~dB}$ beamwidth is observed close to $25^{\circ}$. The side lobe levels are distributed unequally due to asymmetry of the modification introduce in the patch. The first side lobe level is $-20 \mathrm{~dB}$ at $-50^{\circ}$ and at $0^{\circ}$ scanning angle. The peak side lobe level is $-10 \mathrm{~dB}$ at $-40^{\circ}$ for the scanning angle of $30^{\circ}$. For the scanning angle of $-30^{\circ}$, the peak side lobe level is $-15 \mathrm{~dB}$ at $10^{\circ}$ correspondingly. The antenna is used for a scan range as far as $\pm 30^{\circ}$. Beyond this range, the array degrades the antenna pattern due to the mutual coupling.

\section{Conclusion}

This design and development of UKM testbed, capable of performing digital beamforming that employed LIEH array antenna operating at $1.88 \mathrm{GHz}-2.22 \mathrm{GHz}$ and DSP based DBS, have been presented in this paper. The UKM testbed has been designed in a modular manner, which simplifies the design, reduces the development time, eases hardware update, and facilitates testing the various modules (e.g., antenna hardware, beamforming unit, and beamforming algorithms) in an independent manner. Custom-designed boards were developed to allow interface for the connector 


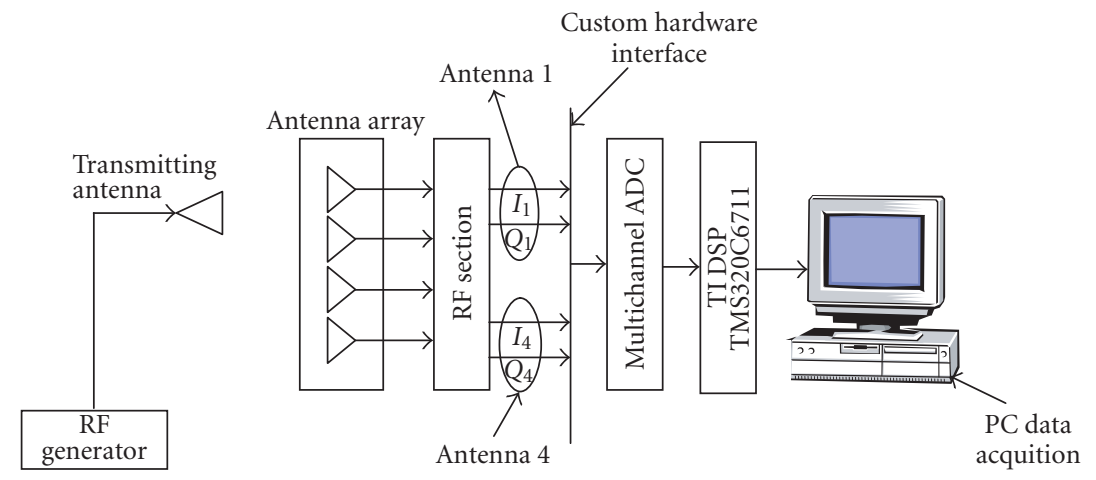

FIGURE 9: UKM testbed receiver experimental setup.

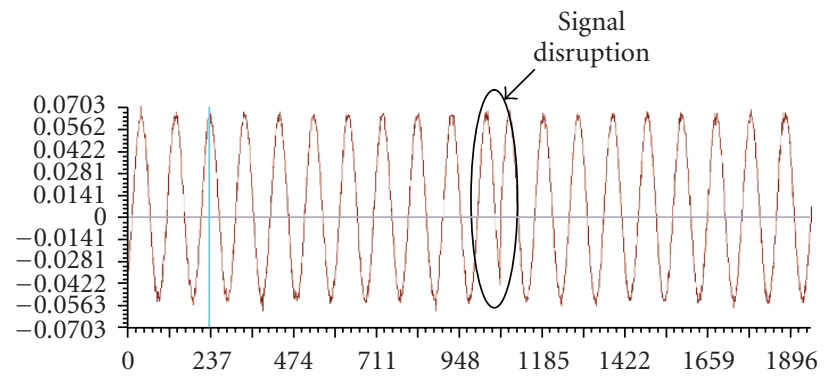

(a)

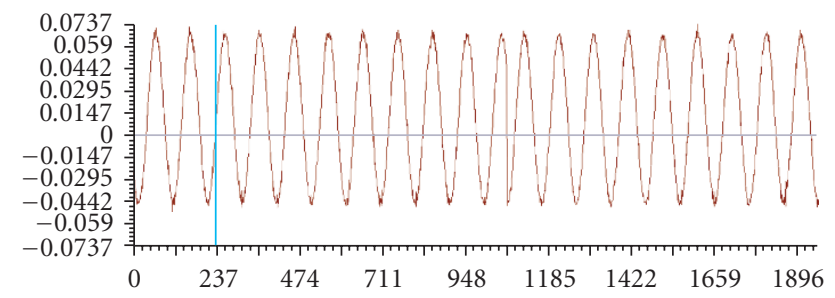

(b)

Figure 10: Channel 1 demodulated $I$ and $Q$ signals using CCS.

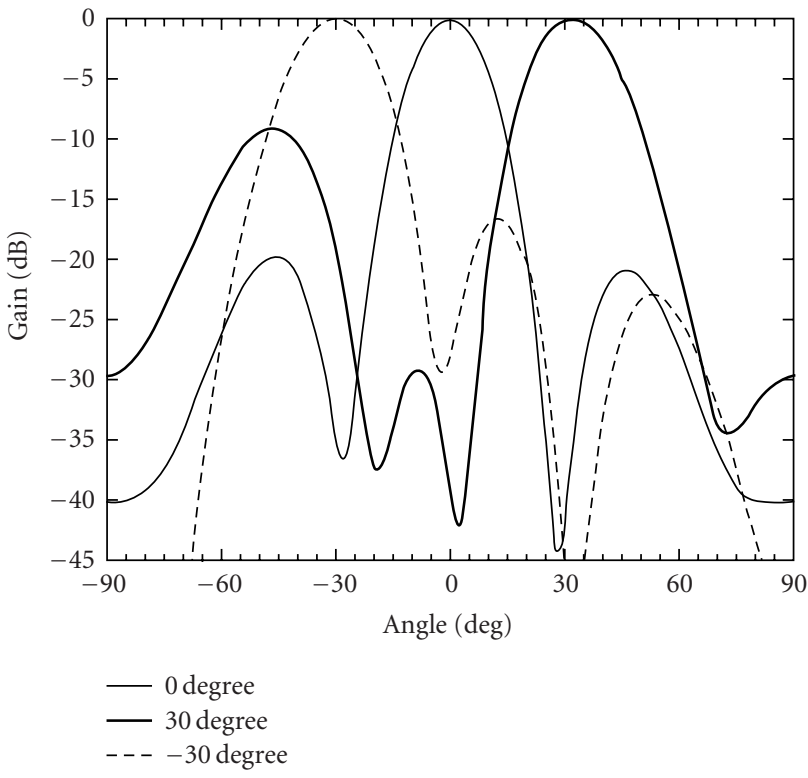

Figure 11: Baseband digital beamforming radiation pattern at the angles $-30^{\circ}, 0^{\circ}$, and $30^{\circ}$.

and voltage level shifting for THS1206 EVM ADC board to work properly. This paper also presented the antenna beampattern of different scanning angles. The capability of digital beamforming has been demonstrated successfully on the UKM testbed. A DSP-based DBS system provided reconfigurability, rapid prototyping, and low-cost imple- mentation. The novel low-cost SATB with its modular design and software reconfigurable approach provided a full $3 \mathrm{G}$ band with small footprint and less weight. The lowcost implementation of the testbed system has proven to be a small budget educational tool to enable researcher to understand practical implementation issues regarding smart antenna system and demonstrate the efficacy of the approach.

\section{Acknowledgments}

The authors would like to thank the IRPA Secretariat, Ministry of Science, Technology and Environmental of Malaysia, IRPA Grant 04-02-02-0029, Institute of Space Science UKM, UKM Grant LL-001-2004, and Zamalah scheme of UKM for sponsoring this work.

\section{References}

[1] S. Ponnekanti, "An overview of smart antenna technology for heterogeneous networks," IEEE Communication Surveys, vol. 2, no. 4, pp. 14-23, 1999.

[2] B. G. Agee, "Blind separation and capture of communication signals using a multitarget constant modulus beamformer," in Proceedings of IEEE Military Communications Conference (MILCOM '89), vol. 2, pp. 340-346, Boston, Mass, USA, October 1989.

[3] H. Krim and M. Viberg, "Two decades of array signal processing research: the parametric approach," IEEE Signal Processing Magazine, vol. 13, no. 4, pp. 67-94, 1996. 
[4] J. C. Liberti and T. S. Rappapoert, Smart Antenna for Wireless Communications Is-95 and Third Generation CDMA Applications, Prentice-Hall PTR, Englewood Cliffs, NJ, USA, 2002.

[5] S. Chen, N. N. Ahmad, and L. Hanzo, "Adaptive minimum bit-error rate beamforming," IEEE Transactions on Wireless Communications, vol. 4, no. 2, pp. 341-348, 2005.

[6] M. C. Wells, "Increasing the capacity of GSM cellular radio using adaptive antennas," IEE Proceedings: Communications, vol. 143, no. 5, pp. 304-310, 1996.

[7] J. D. Fredrick, Y. Wang, and T. Itoh, "A smart antenna receiver array using a single RF channel and digital beamforming," IEEE Transactions on Microwave Theory and Techniques, vol. 50, no. 12, pp. 3052-3058, 2002.

[8] J. Litva and T. K. Y. Lo, Digital Beamforming in Wireless Communications, Artech House, London, UK, 1996.

[9] L. C. Godara, "Applications of antenna arrays to mobile communications-part I: performance improvement, feasibility, and system considerations," Proceedings of the IEEE, vol. 85, no. 7, pp. 1031-1060, 1997.

[10] I. S. Reed, J. D. Mallett, and L. E. Brennan, "Rapid convergence rate in adaptive arrays," IEEE Transactions on Aerospace and Electronic Systems, vol. 10, no. 6, pp. 853-863, 1974.

[11] M. W. Ganz, R. L. Moses, and S. L. Wilson, "Convergence of the SMI and the diagonally loaded SMI algorithms with weak interference [adaptive array]," IEEE Transactions on Antennas and Propagation, vol. 38, no. 3, pp. 394-399, 1990.

[12] B. Widrow, P. E. Mantey, L. J. Griffiths, and B. B. Goode, "Adaptive antenna systems," Proceedings of the IEEE, vol. 55, no. 12, pp. 2143-2159, 1967.

[13] L. J. Griffiths, "A simple adaptive algorithm for real-time processing in antenna arrays," Proceedings of the IEEE, vol. 57, no. 10, pp. 1696-1704, 1969.

[14] S. Caban, C. Mehlführer, R. Langwieser, A. L. Scholtz, and M. Rupp, "Vienna MIMO testbed," EURASIP Journal on Applied Signal Processing, vol. 2006, Article ID 54868, 13 pages, 2006.

[15] F. Adachi, M. Sawahashi, and H. Suda, "Wideband DS-CDMA for next-generation mobile communications systems," IEEE Communications Magazine, vol. 36, no. 9, pp. 56-69, 1998.

[16] S. Choi and D. Yun, "Design of an adaptive antenna array for tracking the source of maximum power and its application to CDMA mobile communications," IEEE Transactions on Antennas and Propagation, vol. 45, no. 9, pp. 1393-1404, 1997.

[17] S. Ohmori, Y. Yamao, and N. Nakajima, "The future generations of mobile communications based on broadband access technologies," IEEE Communications Magazine, vol. 38, no. 12, pp. 134-142, 2000.

[18] C. M. Simmonds and M. A. Beach, "Downlink stability evaluations of the TSUNAMI (II) adaptive antenna testbed," in Proceedings of the 3rd ACTS Mobile Communications Summit, pp. 417-423, Rhodes, Greece, June 1998.

[19] R. Gozali, R. Mostafa, R. C. Palat, et al., "Virginia tech space-time advanced radio (VT-STAR)," in Proceedings of the Radio and Wireless Conferrence (RAWCON '01), pp. 227-231, Waltham, Mass, USA, August 2001.

[20] K.-L. Lau, K.-M. Luk, and K.-F. Lee, "Design of a circularlypolarized vertical patch antenna," IEEE Transactions on Antennas and Propagation, vol. 54, no. 4, pp. 1332-1335, 2006.

[21] Y. P. Zhang and J. J. Wang, "Theory and analysis of differentially-driven microstrip antennas," IEEE Transactions on Antennas and Propagation, vol. 54, no. 4, pp. 1092-1099, 2006.

[22] M. T. Islam, N. Misran, and N. K. Jiunn, "A $4 \times 1$ L-probe fed inverted hybrid E-H microstrip patch antenna array for $3 \mathrm{G}$ application," American Journal of Applied Sciences, vol. 4, no. 11, pp. 897-901, 2007.

[23] S. C. Gao, L. W. Li, M. S. Leong, and T. S. Yeo, "A novel dualpolarized, wide-band microstrip patch antenna with aperture coupling," in Proceedings of IEEE Antennas and Propagation Society International Symposium, vol. 4, pp. 78-81, Boston, Mass, USA, July 2001.

[24] T. Huynh and K.-F. Lee, "Single-layer single-patch wideband microstrip antenna," Electronics Letters, vol. 31, no. 16, pp. 1310-1312, 1995.

[25] T. Huynh, K. F. Lee, and R. Q. Lee, "Crosspolarisation characteristics of rectangular patch antennas," Electronics Letters, vol. 24, no. 8, pp. 463-464, 1988.

[26] Texas Instruments, “Code Composer Studio IDE," November 2008, http://focus.ti.com/docs/toolsw/folders/print/ccstudio .html. 